\title{
Unraveling the causes of excess lead in drinking water supply systems of densely populated high-rise buildings in Hong Kong
}

\author{
Shu Ning Chan ${ }^{1}$, Lu Chang ${ }^{1}$, King Wah Choi ${ }^{1}$, Joseph H.W. Lee ${ }^{1,2}$, \\ John K. Fawell ${ }^{3}$, and Kelvin Y.T. Kwok ${ }^{4}$ \\ ${ }^{1}$ Department of Civil and Environmental Engineering, The Hong Kong University \\ of Science and Technology, Hong Kong, China \\ ${ }^{2}$ Institute for Advanced Study, The Hong Kong University of Science and \\ Technology, Hong Kong, China \\ ${ }^{3}$ Water Science Institute, Cranfield University, Cranfield MK43 OAL, UK \\ ${ }^{4}$ Formerly, Water Supplies Department, The Hong Kong Special Administrative \\ Region Government, Hong Kong, China
}

\section{Supporting Information}

\section{Field sampling for Public Rental Housing (PRH) estate households}

1.1 Overview of drinking water supply system for high rise buildings in Hong Kong

In Hong Kong, the drinking water is first delivered from water treatment plants to service reservoirs located at high elevations on the hills, then fed to the public distribution network by gravity. For a high-rise building of 30-40 storeys, the water is normally first pumped to a roof tank from the mains (c.f. Figure 1a in the paper) and delivered to the floors below by gravity along a "down pipe" (diameter $\approx 70 \mathrm{~mm}$ ). Water supply to the lower floors may also be supplied directly from the mains without passing through the sump tank and roof tank system. Each building has a number of downpipes serving different sections/ "wings" of the building.

On every floor, the down pipe is connected to a distribution cluster (the meter room) where it branches out to individual flats. Typically, a 
supply chain from the down pipe to the flat consists of 10-20 m long copper pipes (typical diameter 20-26 mm) connected with soldered joints (sockets, elbows) and a number of fixtures (water meters, valves and faucets) (Fig. 1b). Inside each flat, the supply chain branches into different locations such as kitchen, bathrooms and washing machines.

As Hong Kong uses sea water for toilet flushing (covering $85 \%$ of the population), the drinking water supply system is entirely separated from the supply for toilet flushing.

\subsection{Field sampling protocol of occupied flats}

A specially designed field sampling of individual households of Public Rental Housing (PRH) Estates was carried out to provide an independent dataset for identification of the sources and causes of excess lead in drinking water, and as a basis for general health risk assessment. The sampling covered 36 buildings in the 11 "affected estates" ( $\mathrm{Pb}$ concentration in fully-flushed samples greater than $(>)$ the WHO provisional guideline value of $10 \mu \mathrm{g} / \mathrm{L}$ ) and 7 buildings in 6 selected "unaffected estates" (Pb concentration in fullyflushed samples less than or equal to $10 \mu \mathrm{g} / \mathrm{L}$, Fig. S1). Each building (30-40 storeys high) is divided into three zones (upper, middle and lower). For each zone, a flat was randomly selected for the sampling. In total, 129 flats were sampled.

The field sampling was conducted by trained researchers from the Hong Kong University of Science and Technology (HKUST) during 2-22 December 2015. There were 6 sampling teams. Each team consisted of two members; at least one member could speak the local dialect (Cantonese) well enough to communicate with the estate management staff from the Government Housing Department (HD) and the residents. Each team was responsible for sampling one building (three flats) each day. All team members were briefed and received training provided by the HKUST Health, Safety and Environment Office (HSEO) Laboratory which is accredited under the Hong Kong Laboratory Accreditation Scheme (HOKLAS) as well as the US AIHA Industrial Hygiene Laboratory Accreditation Program. A briefing session was conducted at $4 \mathrm{pm}$ the day before every sampling day on the contact points and details of the next-day sampling. Sampling bottles were provided by HSEO together with sampling forms and other apparatus (one 1 litre bottle and one $250 \mathrm{~mL}$ measuring cylinder for flow rate measurement).

The resident was instructed by the estate management staff to flush the kitchen and wash basin taps the night before the sampling day for 5 minutes before going to bed, and not to use the kitchen tap afterwards before the sampling. In case a filter was installed, the filter was removed by an approved contractor the day before sampling.

Field samplings were conducted between 6:30 am and 9:00 am. The teams would meet with the government staff for briefing before commence- 
ment of the sampling. The sampling procedure is as follows:

1. The sampling team briefed the residents the sampling exercise. The residents were asked two questions - (i) if kitchen and wash basin taps have been flushed for 5 minutes the day before; and (ii) if kitchen and wash basin taps have been used again after the flushing.

2. The kitchen tap was turned fully open to the cold water side with the first sample $(250 \mathrm{~mL})$ collected immediately at time zero. The tap remained open throughout the sampling.

3. The second, third, fourth and fifth samples $(50 \mathrm{~mL}$ each, except the fifth sample of the third flat of each building, which was a $250 \mathrm{~mL}$ sample for quality control purpose) were collected at 20, 40, 60 and 80 seconds after the tap was turned on.

4. The sample identification number was recorded on the sampling form. Any potential contamination and other relevant information were also recorded. A photo of the kitchen tap was taken using smartphone or camera for recording the type of faucet.

5. Flow rate measurement: Water was collected using a 1 litre bottle; the time required to collect approx. $1 \mathrm{~L}$ of water was recorded. The exact volume of the water collected was measured using the $250 \mathrm{~mL}$ measuring cylinder provided.

\subsection{Field sampling protocol of vacant flats}

Special sampling surveys were also conducted in 3 vacant flats of three estates (Un Chau, Kwai Luen, Kai Ching). Two sampling taps were installed: (i) at the water meter position inside the meter room; and (ii) at the location of pipe entry inside the flat. The kitchen and wash basin taps were flushed by the government staff for $5 \mathrm{~min}$ the day before. Samples were taken at the sampling and kitchen taps. The pipe configuration of each flat was also measured on site for CFD modeling.

The sampling procedure is as follows:

1. One $250 \mathrm{~mL}$ sample was collected at the meter room tap.

2. One $250 \mathrm{~mL}$ sample was collected at the tap at the entry of the water supply pipe to the flat.

3. The first sample $(250 \mathrm{~mL})$ at the kitchen tap was collected when the tap was opened. The tap remained fully open throughout the sampling. 
4. The second, third, fourth, fifth and sixth samples (50 $\mathrm{mL}$ each) were collected at $\mathrm{t}=30,60,120,180$ and 300 seconds at the kitchen tap.

5. The kitchen tap flow rate was measured using a $1 \mathrm{~L}$ bottle and a measuring cylinder.

6. After the flow rate measurement (which took around 5 minutes), one $250 \mathrm{~mL}$ sample was collected again at the meter room tap.

7. One $250 \mathrm{~mL}$ sample was again collected at the tap at the pipe entry to the flat.

8. After around 3-4 hours of stagnation, the vacant flat was revisited and steps 1-7 were carried out again to collect one more set of samples.

\subsection{Post-Sampling and analysis of samples}

After the sampling, the samples were transported back to HKUST. All samples were preserved and logged in by HSEO; a certain proportion of samples were sent to the Government Laboratory (GL) around noon time by HSEO staff. The water samples were analyzed for lead, copper and nickel. A total of 645 samples were collected; 290 samples were analyzed by GL and 355 samples by HSEO Lab. Eighteen samples analyzed by both GL and HSEO Lab of HKUST were used for cross checking. For samples with lead concentration less than or equal to around $10 \mu \mathrm{g} / \mathrm{L}$, the differences were typically less than $1 \mu \mathrm{g} / \mathrm{L}$; the mean difference of lead concentration is around $2 \mu \mathrm{g} / \mathrm{L}$ over the range of 0-50 $\mu \mathrm{g} / \mathrm{L}$ (not shown; see also comparison in Fig. S5).

A total of 80 samples were collected for vacant flats; 40 samples were analyzed by HSEO Laboratory and 40 samples by GL.

An analysis of the distribution of $\mathrm{PRH}$ estate building $\mathrm{Pb}$ data shows that overall about $71 \%$ of the samples have a lead concentration less than $20 \mu \mathrm{g} / \mathrm{L}$, while only $1 \%$ of the samples have a concentration of over 1000 $\mu \mathrm{g} / \mathrm{L}$. High $\mathrm{Pb}$ concentration of over $100 \mathrm{ppb}$ was rarely observed $(\sim 10 \%)$ in our PRH Estate household sampling.

\subsection{Measured flow rates at the tap}

A histogram of the measured flow rates is shown in Fig. S2. The flow rate varied from 0.051 to $0.603 \mathrm{~L} / \mathrm{s}$, with a mean of $0.261 \mathrm{~L} / \mathrm{s}$ and standard deviation of $0.08 \mathrm{~L} / \mathrm{s}(N=131)$. The generally higher flow rates in our study as compared with values reported in the literature (e.g. 3-10 L/min or $0.05-0.167 \mathrm{~L} / \mathrm{s}$, Clark et al. 2014) can be attributed to the generally higher head in the supply chain of high rise buildings in Hong Kong. A pressure head difference of 30-50 m (10-20 storeys) between the roof tank and the household can be generated even in the middle floors. For lower 
floors, pressure reducing valves are often installed to reduce the pressure head to avoid excessive flows.

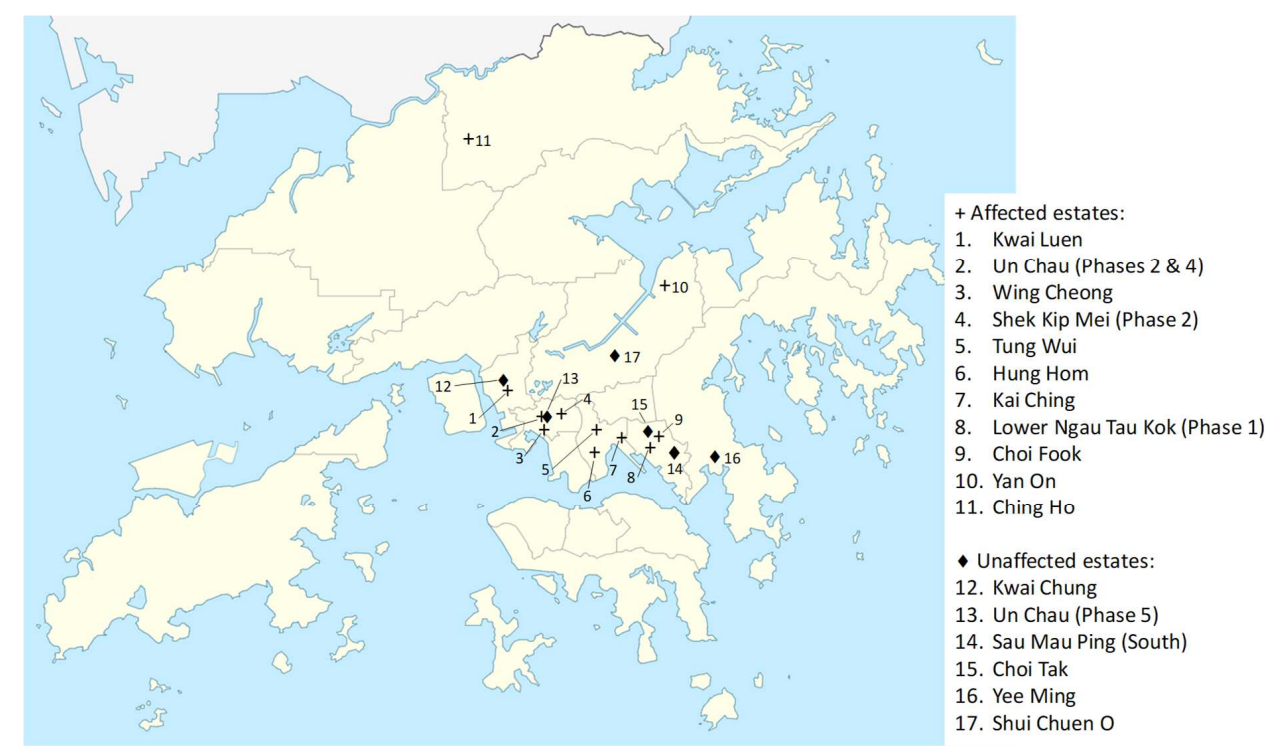

Figure S1: Location of "affected" and "unaffected" Public Rental Housing (PRH) estates in Hong Kong during the 2015 "lead water" episode.

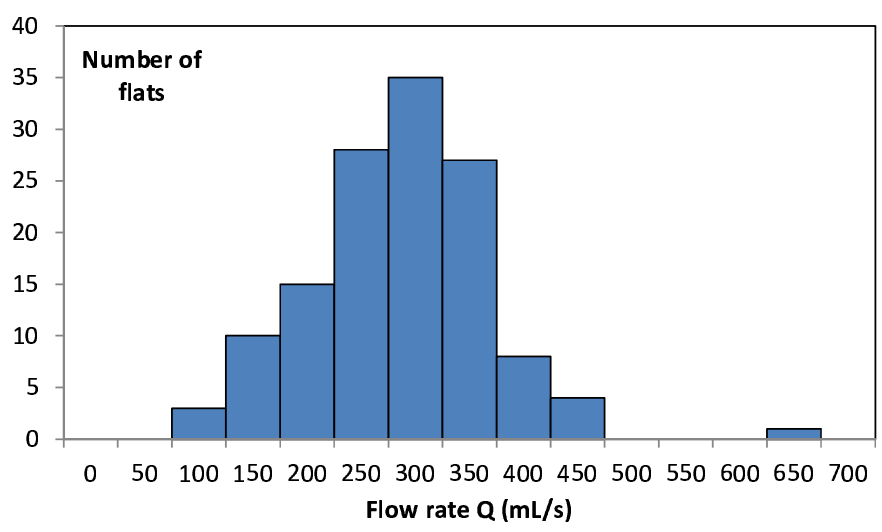

Figure S2: Histogram of measured flow rate of PRH flats $(N=131)$. 


\section{Sampling protocol for experiments on real life water supply chains}

The objective of this series of experiments is to investigate the key contributing component of excess lead in drinking waters inside a typical drinking water supply line in high rise buildings in Hong Kong. The experiments are aimed at obtaining the lead concentration distribution along the supply chain and the dependence of lead concentration on stagnation time. Lead-contaminated water supply chains were dismantled from the public rental housing (PRH) estates and reconstructed at the Electrical and Mechanical Workshop of the Water Supplies Department of the Hong Kong Government (Fig. S3a). In addition to contaminated supply chains, clean pipes without lead solders were also constructed with copper pipe and brass fixtures (valves, water meters and faucets) only. Three lead-contaminated supply lines including one lead solder-free supply line were selected. Their physical characteristics are listed in Table S1 and the layout of one of the supply chains is shown in Fig. S3b.

All the sampling work was implemented under the following protocol (Fig. S4):

1. Each supply line was flushed by fully opening the tap for at least five minutes on the day before sampling.

2. On the day of sampling, at the beginning of an experiment the tap was first opened to a desired setting and the first sample $(250 \mathrm{~mL})$ was collected, followed immediately by collection of the second 750 $\mathrm{mL}$ sample using a graduated $1 \mathrm{~L}$ bottle.

3. The third, fourth, fifth and sixth samples $(50 \mathrm{~mL}$ each $)$ were collected at a fixed time interval (say $20 \mathrm{~s}$ ) keeping the flow running.

4. The flow rate was measured using the $1 \mathrm{~L}$ bottle and measuring cylinder. The time required to collect approximately $1 \mathrm{~L}$ of water was recorded.

5. The samples were stored in a refrigerator before delivery to the WSD or HSEO Laboratory for lead concentration measurement.

A total of about 400 samples were collected in these experiments, with stagnation periods of 0.5 to 93 hours. The $\mathrm{Pb}$ concentration was measured using Inductively Coupled Plasma Mass Spectrometry (ICP-MS) with a detection limit of $1 \mu \mathrm{g} / \mathrm{L}$. Seven samples were split in half and delivered to both laboratories for cross-checking; Fig. S5 shows the results from the two laboratories which agree well to within a root-mean-square difference of 0.46 $\mu \mathrm{g} / \mathrm{L}$ over a range of $0-30 \mu \mathrm{g} / \mathrm{L}$. 
Fig. S6 shows representative measurements of the time variation of lead concentration at the tap, $C(t)$, plotted as a function of distance from the tap (by Galilean transformation), $C(x)$. Fig. S6a shows measured lead concentrations in a test rig (4R, Table $\mathrm{S} 1$ ) without lead solder and only commercially available fittings and clean copper pipes. It is interesting to note the very low (near detection limit) $\mathrm{Pb}$ concentrations around the lead-free solder joints $(\mathrm{N})$. On the other hand, with increase in stagnation period, the lead concentration near the various fixtures $(\mathrm{M}, \mathrm{V})$ can be higher than $5 \mu \mathrm{g} / \mathrm{L}$ and even approach the WHO provisional guideline value. As a sharp comparison, for a lead-solder contaminated test rig $(2 \mathrm{~A})$, the lead concentrations are substantially above $10 \mu \mathrm{g} / \mathrm{L}$, with peak concentration of $60 \mu \mathrm{g} / \mathrm{L}$ after $18 \mathrm{~h}$ stagnation at a solder joint around a bend (Fig. S6b); the turbulence induced by flow separation around a bend may also enhance the possibility of picking up of lead particulates.

Table S1: Summary characteristics of real life water supply chains (test rigs) used in controlled experiments of lead sampling.

\begin{tabular}{lccc}
\hline \hline Supply Line (Test Rig) & $4 \mathrm{R}$ & $3 \mathrm{C}$ & $2 \mathrm{~A}$ \\
\hline Pipe diameter (mm) & 19.5 & 26 & 19.5 \\
Pipe length $(\mathrm{m})$ & 10 & 18 & 16.5 \\
No. of lead-solder joints & 0 & 5 & 15 \\
No. of brass components & 4 & 8 & 9 \\
No. of water samples & 92 & 141 & 59 \\
Flow rate range $(\mathrm{mL} / \mathrm{s})$ & $30-120$ & $37-110$ & $100-176$ \\
\hline
\end{tabular}




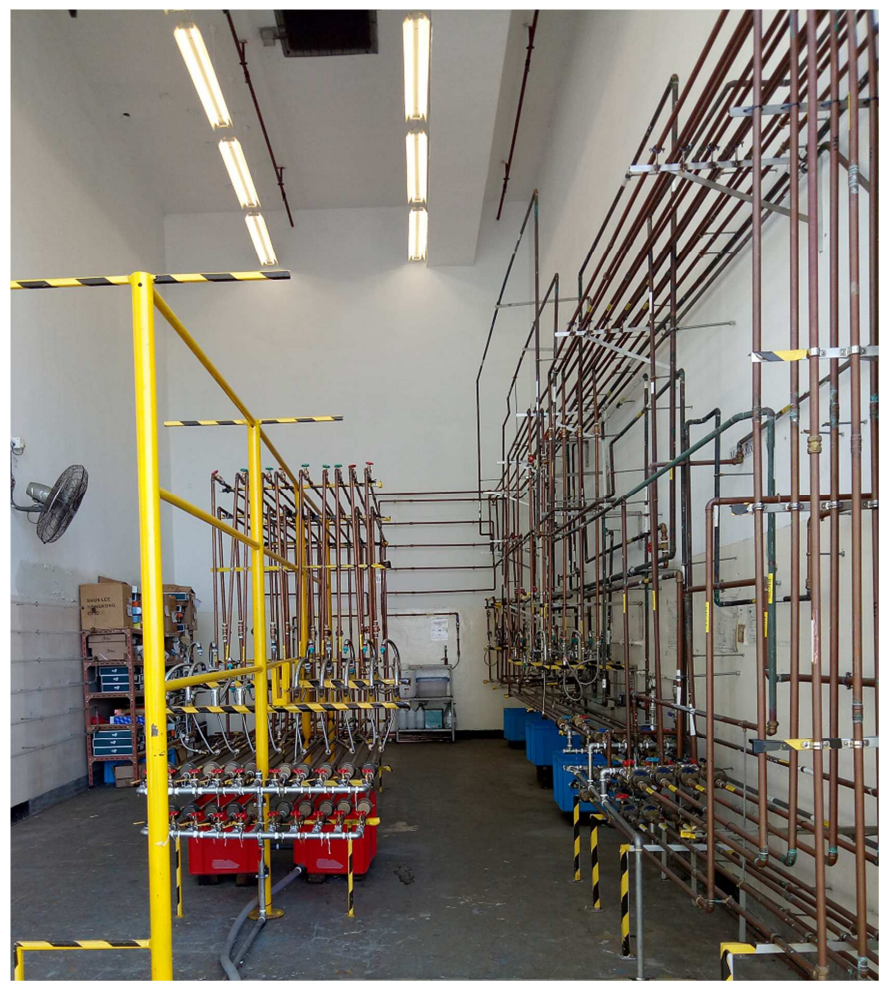

(a)

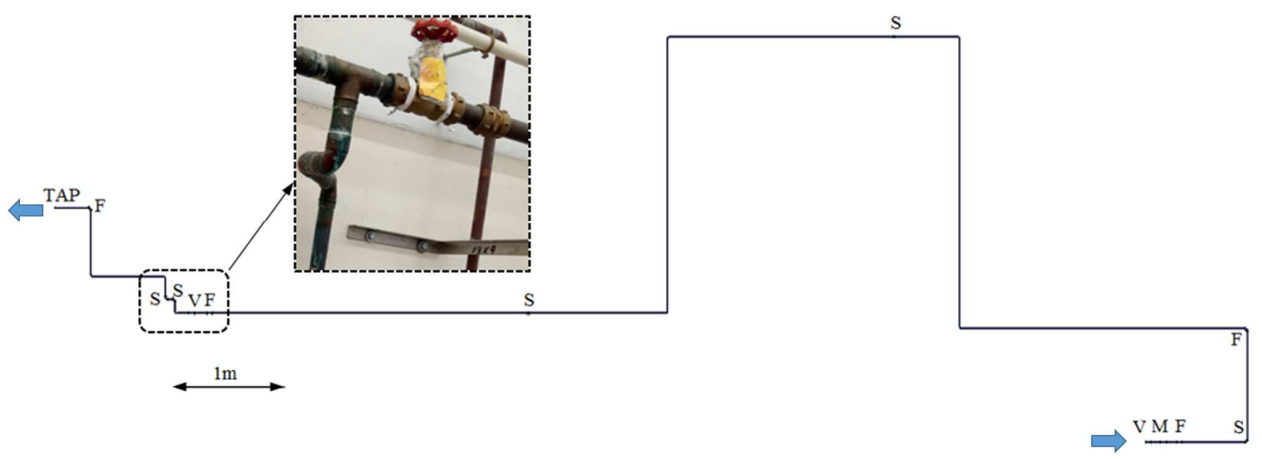

(b)

Figure S3: (a) Real life water supply chains reconstructed from dismantled pipe work from PRH estates. (b) Layout of a typical drinking water supply line in a PRH high-rise building (Rig $3 \mathrm{C}$, Table $\mathrm{S} 1$ ) - V: valve, M: water meter, F: compression joint, S: lead-solder. 


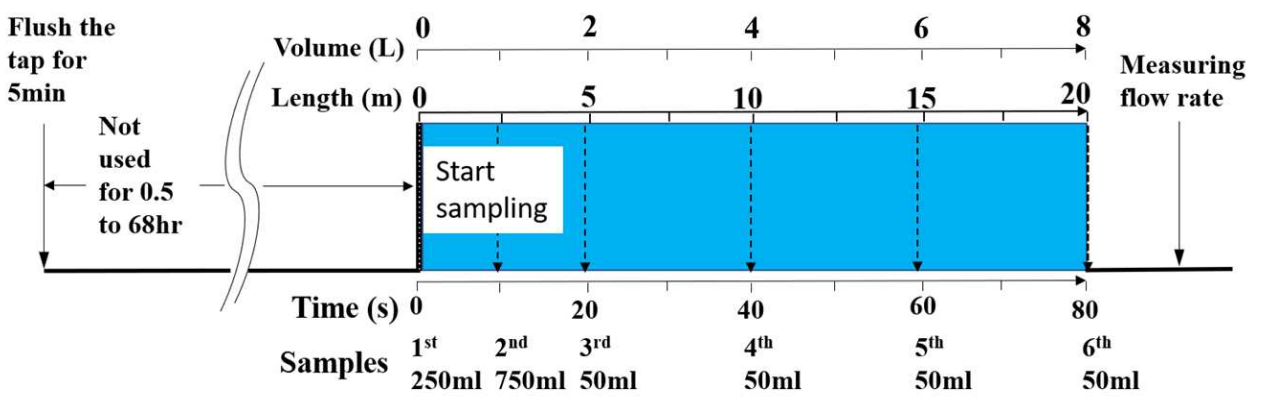

Figure S4: Sampling protocol in experiments on real life water supply chains.

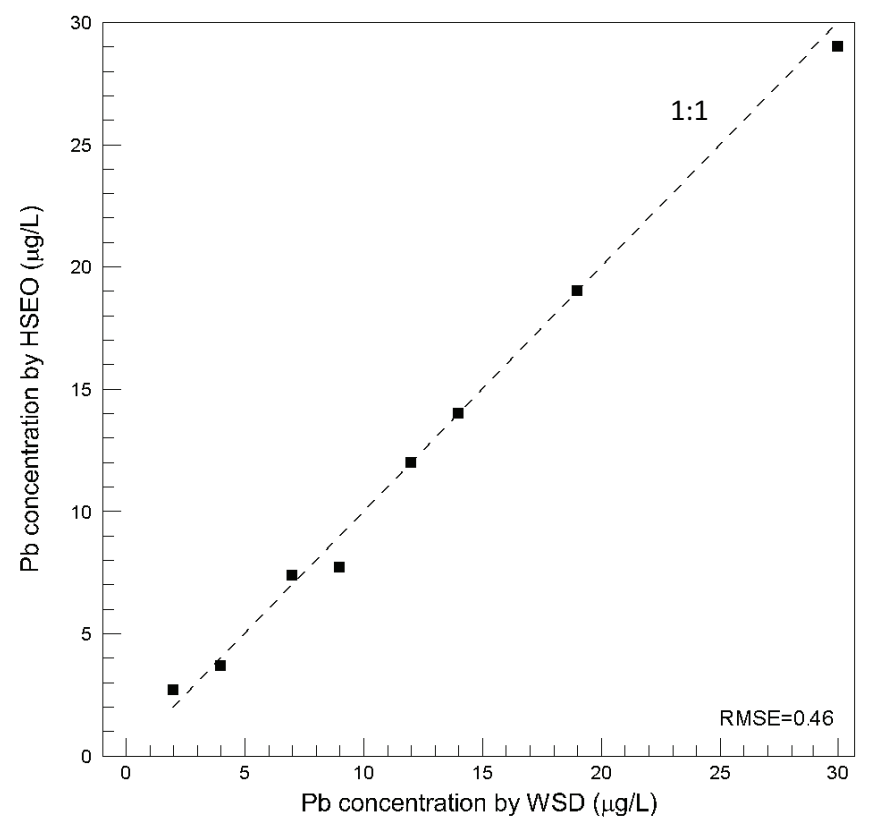

Figure S5: Cross checking of lead concentrations analyzed by WSD and HKUST HSEO laboratories. 


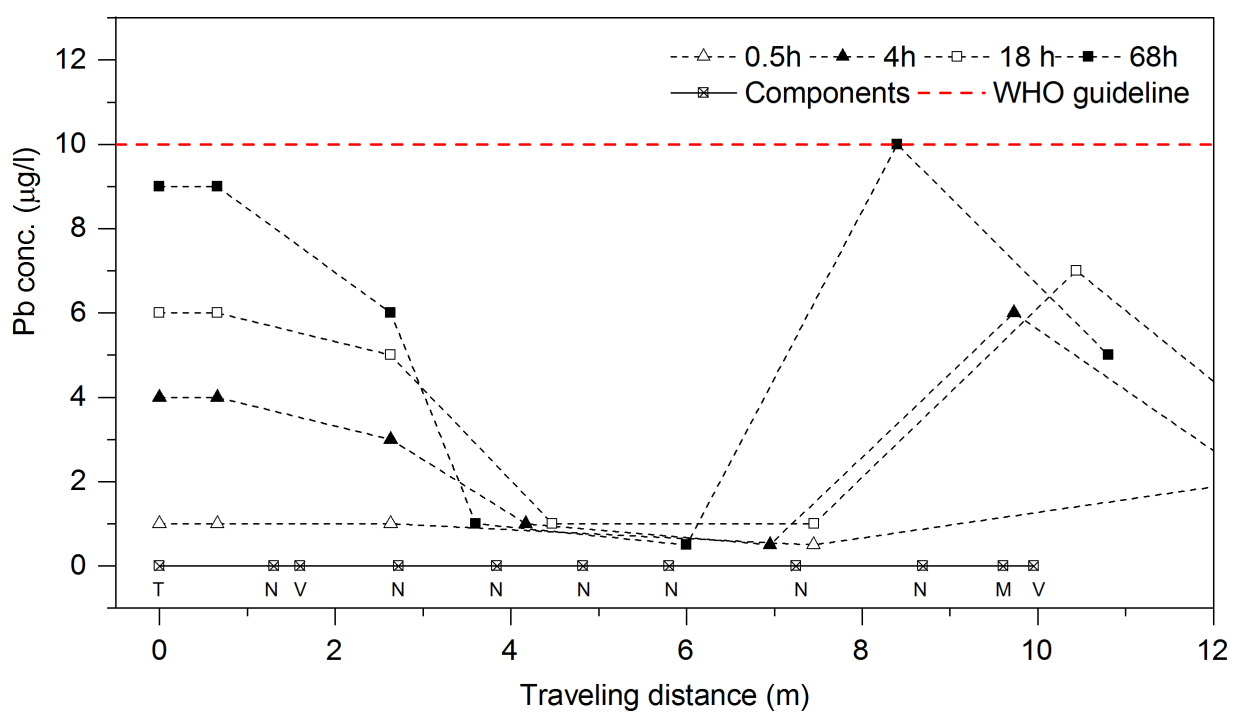

(a)

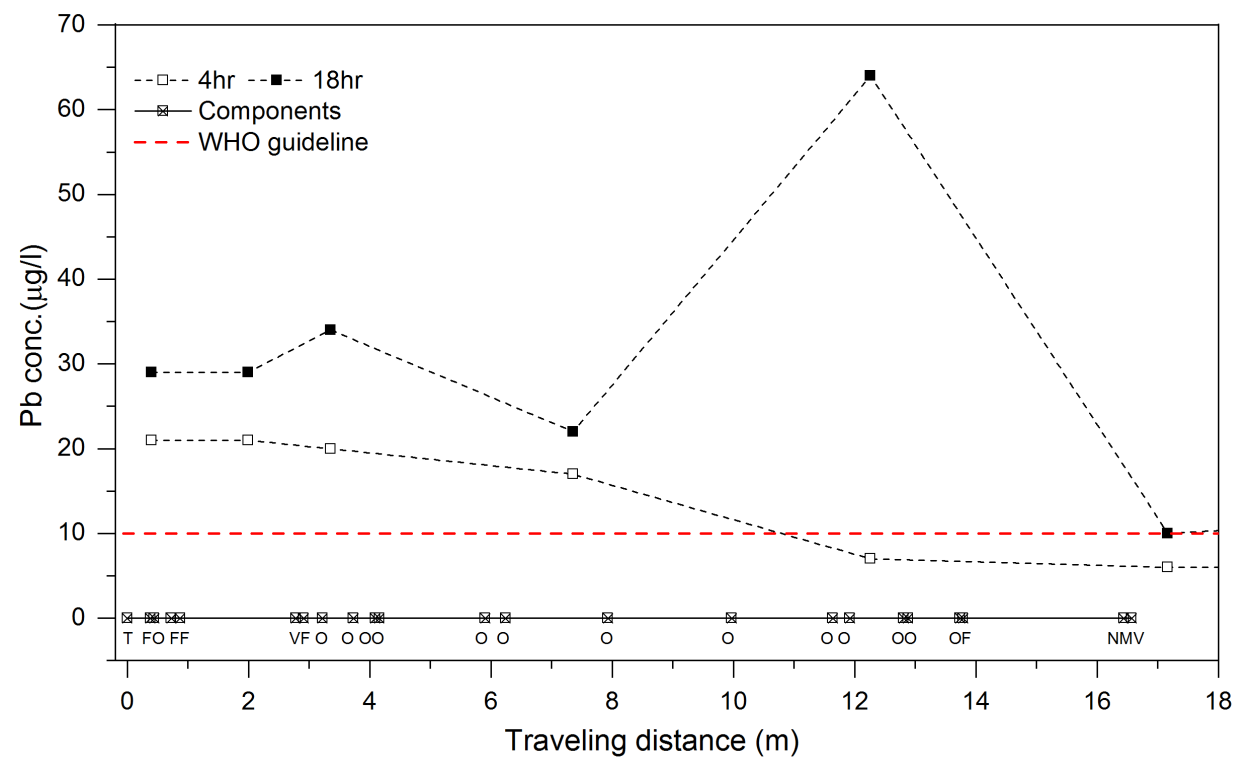

(b)

Figure S6: Measured lead concentration distribution along water supply chain obtained by Galilean transformation of sampling data at the tap: (a) Rig 4R (no lead solder joints); (b) Rig 2A (with lead-solder joints). Location of different types of fixtures also shown: T: tap, S: lead-solder joint, F: compression joint, $\mathrm{N}$ : lead-free solder joint, $\mathrm{M}$ : water meter, $\mathrm{V}$ : valve. 


\section{Computational Fluid Dynamics Modelling}

A three-dimensional (3D) unsteady computational fluid dynamics (CFD) model is used for investigating the accumulation of dissolved lead in stagnation and its mixing and transport in flowing condition. The CFD modeling is carried out in two steps:

1. First, the 3D diffusion of lead from the small size lead source on the pipe wall into the fluid interior is computed, providing the initial conditions for the mixing and transport in the turbulent flow after the tap turned on.

2. Second, the mixing and transport of the "diffusion clouds" from the different sources in the flowing environment is obtained by solving the 3D Reynolds-Averaged Navier-Stokes (RANS) equations - giving the spatial and temporal distribution of lead along the pipe.

Our leaching tests (see next section) to measure soluble and particulate lead showed that particulate lead $(<0.8 \mu \mathrm{m})$ is not significant in our system. Abokifa and Biswas (2017) showed that lead particles with diameter as large as $57 \mu \mathrm{m}$ will become fully suspended by the turbulent flow. Thus in our CFD model, lead is treated as a passive scalar, and particulate settling and re-suspension are not modelled.

\subsection{Modeling of lead leaching during stagnation}

The lead-leaching process from the small size lead containing components on the pipe wall into the fluid interior is a 3D diffusion process that needs to be accurately modelled to provide the correct initial conditions for the mixing and transport in the turbulent pipe flow. In stagnant condition, the leaching of lead from the pipe wall and fixture surface into the water is governed by molecular diffusion. It is assumed that immediately adjacent to the pipe wall, the dissolved lead concentration is in the maximum equilibrium concentration $C=E_{0}$ (Kuch and Wagner, 1983; Van der Leer et al, 2002). The 3D diffusion process in the water supply chain can be described by a Fickian diffusion equation:

$$
\frac{\partial C}{\partial t}=D\left(\frac{\partial^{2} C}{\partial x^{2}}+\frac{\partial^{2} C}{\partial y^{2}}+\frac{\partial^{2} C}{\partial z^{2}}\right)
$$

where $C(x, y, z, t)$ is the lead concentration in water; $(x, y, z)$ are the spatial coordinates; $t$ is the time; $D \approx 10^{-9} \mathrm{~m}^{2} / \mathrm{s}$ is the molecular diffusivity of lead in water. In this formulation, the leaching rate of lead decrease with time as the water becomes more saturated with lead. 


\subsection{Modeling of lead transport in flowing condition}

With the water tap turned on, it is assumed that the flow in the relatively short water supply chain $(\approx 15-30 \mathrm{~m})$ attains steady state immediately. The lead accumulated during stagnation will be transported by the turbulent pipe flow to the open tap. The lead will be mixed over the cross-section by the turbulence, and the "lead clouds" from different sources disperse longitudinally by the transverse velocity profile. The interaction of crosssectional mixing and shear dispersion of the lead clouds is best modeled by a fully $3 \mathrm{D}$ model without the need to make any assumptions.

The mixing and transport of lead in the steady pipe flow is governed by the advective-diffusion equation:

$\frac{\partial C}{\partial t}+\frac{\partial(u C)}{\partial x}+\frac{\partial(v C)}{\partial y}+\frac{\partial(w C)}{\partial z}=\frac{\partial}{\partial x}\left(E_{T} \frac{\partial C}{\partial x}\right)+\frac{\partial}{\partial y}\left(E_{T} \frac{\partial C}{\partial y}\right)+\frac{\partial}{\partial z}\left(E_{T} \frac{\partial C}{\partial z}\right)$

where $[u, v, w]$ is the velocity field and $E_{T}$ is the turbulent diffusivity determined by the $k-\epsilon$ model. $E_{T}$ is typically in the order of $10^{-2}-10^{-3} \mathrm{~m}^{2} / \mathrm{s}$, several orders of magnitude higher than the molecular diffusivity.

\subsection{CFD Computation details}

The solutions of Eqs. S1 \& S2 are obtained numerically using the ANSYS FLUENT 3D CFD code. The model grid is generated based on the measured pipe system geometry. The pipe section between the downpipe and the kitchen tap for a typical flat is modelled. Boundary-fitted tetrahedral and hexagonal grid cells are used, with minimum grid cell size of $\sim 1 \mathrm{~mm}$. Meters, valves are modelled similar to a short pipe section of $5 \mathrm{~cm}$. For a typical water supply chain of a PRH estate flat, 800,000 to 1,000,000 grid cells are used.

Figure S7 shows the typical CFD grid for various locations of a supply chain of a flat, including the connection of the downpipe ( $\approx 70 \mathrm{~mm}$ diameter) with the pipe leading to the meter room, the tee-branch in the meter room and other locations. Figure S8 shows the CFD model grid for the bends and change in pipe diameter from the main supply chain to the tap.

For stagnant condition, Eq. S1 is solved. For flowing condition, a steadystate solution of the velocity field is first predicted with prescribed flow rate at inflow and zero-pressure at the outlet (tap). The computed 3D velocity field in the pipe system is then used for predicting the lead transport (Eq. S2). The time step for the molecular diffusion computation is 10-20s, while that for transport in flowing water is $0.01-0.05 \mathrm{~s}$.

\subsection{Determination of the equilibrium concentration $E_{0}$}

Stagnation leaching tests 
Stagnation tests were carried out for a soldered joint, a brass valve and a copper pipe section with lead carbonate deposits respectively. Fig. S9a shows a schematic diagram of the leaching experiment for a brass valve coupled with two $10 \mathrm{~cm}$ long pipe sections on either side. After a certain stagnation period, the fully mixed or average $\mathrm{Pb}$ concentration $\left(\overline{C_{m}}\right)$ in the volume of the leaching experimental apparatus is measured - from which the total mass of leached lead can be obtained. The water quality parameters in our stagnation leaching tests are quite stable with temperature $\approx 20^{\circ} \mathrm{C}$, total residual chlorine $(\mathrm{TRC})=0.4-0.5 \mathrm{mg} / \mathrm{l}$, dissolved oxygen $(\mathrm{DO})=7.8-8.3$ $\mathrm{mg} / \mathrm{l}$. For each test component, triplicate leaching tests have been carried out. The standard deviations of $\overline{C_{m}}$ are in the order of $10-20 \%$ of the mean.

It should be noted that $\overline{C_{m}}$ is fundamentally different from $E_{0}$. At small stagnation time, the $\mathrm{Pb}$ has not yet diffused sufficiently into the interior of the bulk water; the $\mathrm{Pb}$ concentration is much smaller at the pipe center. After long stagnation time, the entire cross section over the length of the lead component attains a concentration similar to $E_{0}$. The longitudinal diffusion along the pipe is however very limited and only spans an axial length in the order of the length of the component (see Fig. 5 in the paper).

Calibration of $E_{0}$

$E_{0}$ is obtained by calibration against the time variation of measured $\overline{C_{m}}$. An initial value of $E_{0}$ is estimated based on the $\overline{C_{m}}$ after 24-hour stagnation, as $E_{0}=\overline{C_{m}} V_{0} /\left(\pi d l_{o}\right)$, where $d=$ pipe diameter, $l_{o}=$ length of component ( $5 \mathrm{~cm}$ for brass valve, $1 \mathrm{~cm}$ for solder joints) - i.e. distributing the total leached lead over the volume of water spanned by the component length (Fig. S9a). A CFD simulation of the leaching process is then performed to predict the time variation of average lead concentration in the pipe $\bar{C}$ :

$$
\bar{C}=\frac{\int C d V}{V_{o}}
$$

where $C(x, y, z)$ and $d V$ are the predicted $\mathrm{Pb}$ concentration and volume of each computational cell respectively; $V_{o}$ is the total volume of the pipe. The relative root mean square error (RMSE) between all measured $\overline{C_{m}}$ and predicted $\bar{C}$ can then be evaluated as:

$$
\operatorname{RMSE}(\%)=\frac{\sqrt{\sum\left(\overline{C_{m}}-\bar{C}\right)^{2} / N_{m}}}{\left(\sum \overline{C_{m}}\right) / N_{m}}
$$

where $N_{\mathrm{m}}$ is the number of measurements. The optimal $E_{0}$ is determined iteratively as the value that gives the minimum RMSE. The numerical prediction corresponding to the initial estimate and best-fitted $E_{0}$ are compared with the experimental data in Figure S10. 
Lead solubility

Using the chemical equilibrium model-MINTEQ (https://vminteq. Iwr. kth.se/), the solubility of different $\mathrm{Pb}$ species for the tap water in our experiments were computed using different $\mathrm{pH}$ values. The following average drinking water quality parameters of Hong Kong (WSD, 2020) are used as input to the MINTEQ model: $\mathrm{CO}_{3}^{2-}=14.4 \mathrm{mg} / \mathrm{L} ; \mathrm{Cl}^{-}=10 \mathrm{mg} / \mathrm{L}$; $\mathrm{SO}_{4}^{2-}=13 \mathrm{mg} / \mathrm{L} ; \mathrm{Ca}^{2+}=11 \mathrm{mg} / \mathrm{L} ; \mathrm{Mg}^{2+}=1.4 \mathrm{mg} / \mathrm{L} ; \mathrm{Al}^{3+}=0.03 \mathrm{mg} / \mathrm{L}$. Measured values of free chlorine $=0.5 \mathrm{mg} / \mathrm{L}$ and dissolved oxygen $=8.0 \mathrm{mg} / \mathrm{L}$ are adopted.

The simulation output of soluble and particulate species in water for $\mathrm{pH}$ $=8.0$ is shown in Fig. S11. The predicted total soluble lead is $23 \mu \mathrm{g} / \mathrm{L}$. Consistent with the literature (Jackson and Sheiham, 1980; Schock, 1999), the major species are the $\mathrm{Pb}^{2+}$ ions, and lead carbonate and hydroxide complexes. As observed in our leaching experiments, the $\mathrm{pH}$ value in the mixed sample can drop from an initial value of 8.1 to 7.5 after several hours of stagnation. Fig. S12 shows that the solubility of $\mathrm{Pb}$ increases by one order of magnitude (from 23 to $246 \mu \mathrm{g} / \mathrm{L}$ ) when the $\mathrm{pH}$ changes from 8 to 7. A locally high soluble lead concentration can be induced by the local $\mathrm{pH}$ changes due to galvanic corrosion near a solder joint or brass valve.

The foregoing results suggest that lead solubility are in the order of 10 to $100 \mu \mathrm{g} / \mathrm{L}$ for the bulk tap water in our experiments. In spite of the lack of detailed measurements of $\mathrm{pH}$ changes in the micro-environment and other complexities, these values are broadly consistent with the $E_{0}$ 's for the pipe deposit $(6 \mu \mathrm{g} / \mathrm{L})$ and brass valve $(260 \mu \mathrm{g} / \mathrm{L})$. Our estimated $E_{0}$ values for leaded solder joints $(1000 \mu \mathrm{g} / \mathrm{L})$ and brass valves are supported by recent experiments of Ma et al. (2018), in which a micro-electrode was developed to measure the lead concentration in the diffusion boundary layer (in the order of $100 \mu \mathrm{m}$ from the solid surface) of a brass-lead galvanic joint in drinking water. $\mathrm{Pb}$ concentrations in the order of $2-10 \mathrm{mg} / \mathrm{L}$ were measured. Although the experimental condition is not directly comparable with ours, their findings suggest that the $\mathrm{Pb}$ concentration near the surface of a lead component can be much higher than that in the bulk water in the leaching process.

\subsection{Uniqueness of the 3D CFD compared to conventional 1D/2D modeling and plug flow assumption}

This is the first 3D CFD calculation for prediction of lead level at the consumer tap for a real life water supply chain, with validation against field data. Previous modeling attempts (e.g. Van der Leer et al, 2002; Abokifa and Biswas, 2017) are mainly 2D ( $x, r)$ in nature - by assuming axi-symmetry and adopting prescribed velocity profiles. Important flow features such as enhanced turbulent mixing around an elbow or longitudinal dispersion (ve- 
locity shear + cross-sectional mixing) cannot be simulated. In 1D/2D models, turbulent mixing coefficients need to be calibrated against experimental data, while in a full 3D simulation, the turbulent diffusivities are predicted from first principles.

To illustrate the importance of turbulent diffusion and shear flow dispersion, the $\mathrm{Pb}$ concentration at the consumer tap of test rig $3 \mathrm{C}$ is predicted for: (i) assuming plug flow with advection only; and (ii) CFD simulated 3D flow. The numerical data is averaged in accordance with the sample volumes. Figure S13 shows that with the plug flow assumption, much higher and isolated concentration peaks would be predicted (see also Fig. 6 in main text). Over the range of typical flows $(0.5-14 \mathrm{~L} / \mathrm{min})$, the assumption of plug flow can result in significant over-estimation of $\mathrm{Pb}$ concentration at the consumer tap. The effect of turbulent diffusion and dispersion can also be seen in the prediction of lead concentration for a supply chain of a PRH estate flat (Fig. S14).

Lead concentration measurements at the level of interest (in the order of 1-10 ppb) is costly - hence the need for the best computational tool for interpreting the limited data. Our 3D CFD model can give an accurate simulation of the tap water lead concentration with a minimum number of assumptions (only calibration of $E_{0}$ 's are needed). The methodology is general and can be applied to any plumbing system using an industrystandard software (e.g. FLUENT or equivalent). This also opens the path for coupling with 1D numerical models which are more efficient in dealing with uncertainties in flow rates and lead source strengths. 


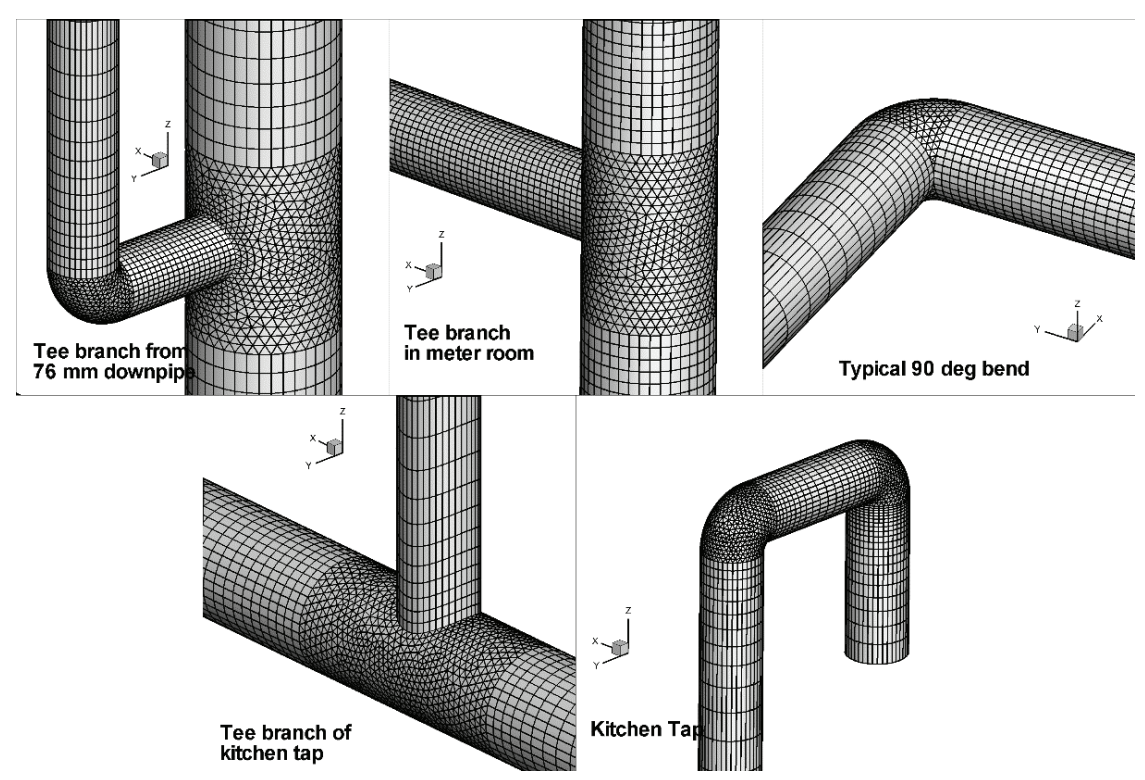

Figure S7: Typical configuration of computational grid of a typical water supply chain in PRH estate flats.

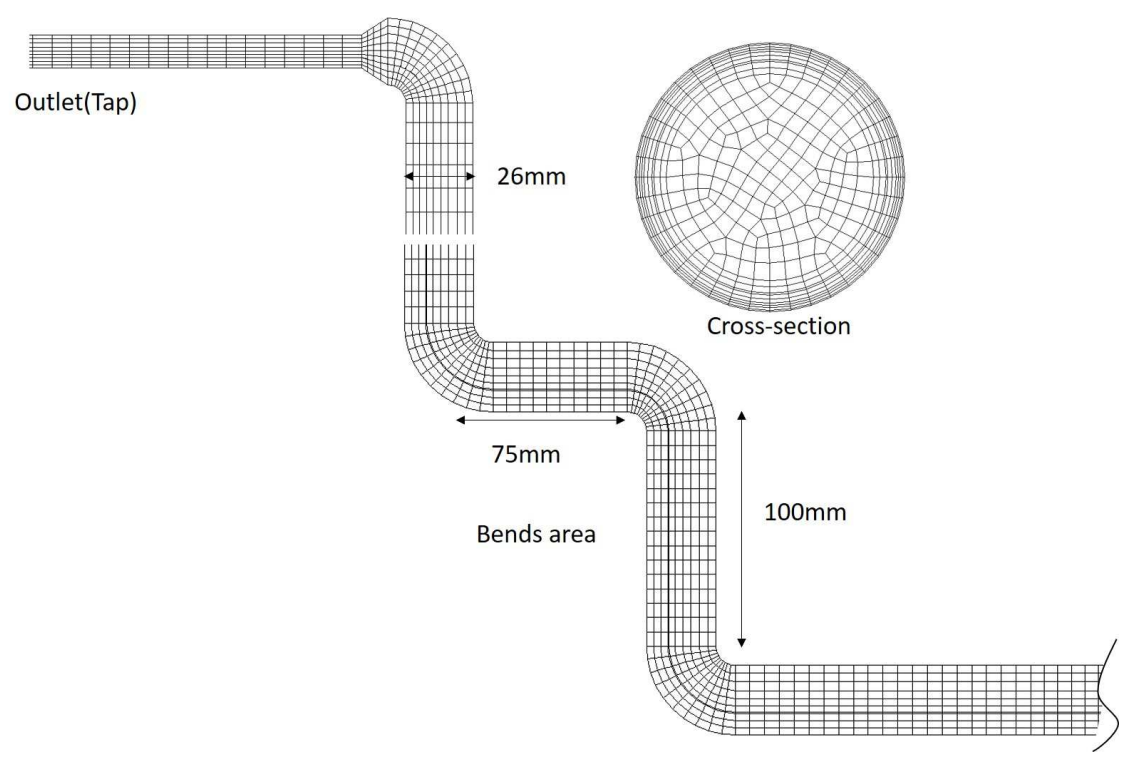

Figure S8: Representative computational grid at bends and pipe diameter change near the tap (outlet) of the test rig (total number of cells $=719,526$; grid size $=0.001-0.0475 \mathrm{~m}$ ) 


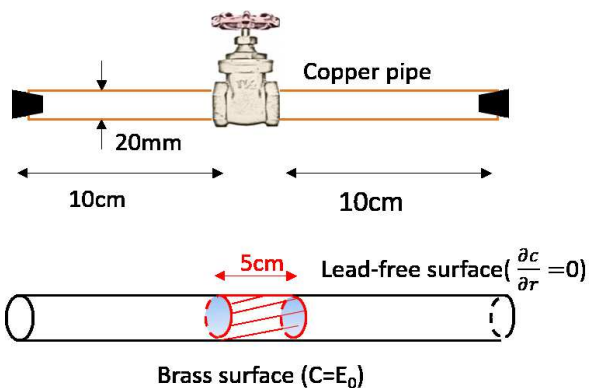

(a)

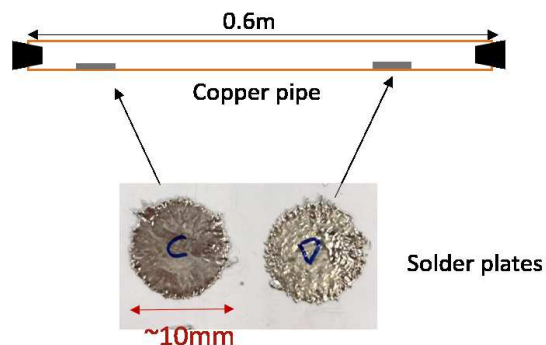

(b)

Figure S9: The schematic layout of experimental pipes for stagnant leaching tests (a) copper pipe coupled with a brass valve at the middle, (b) simulated soldered joint with the size of the solder discs.

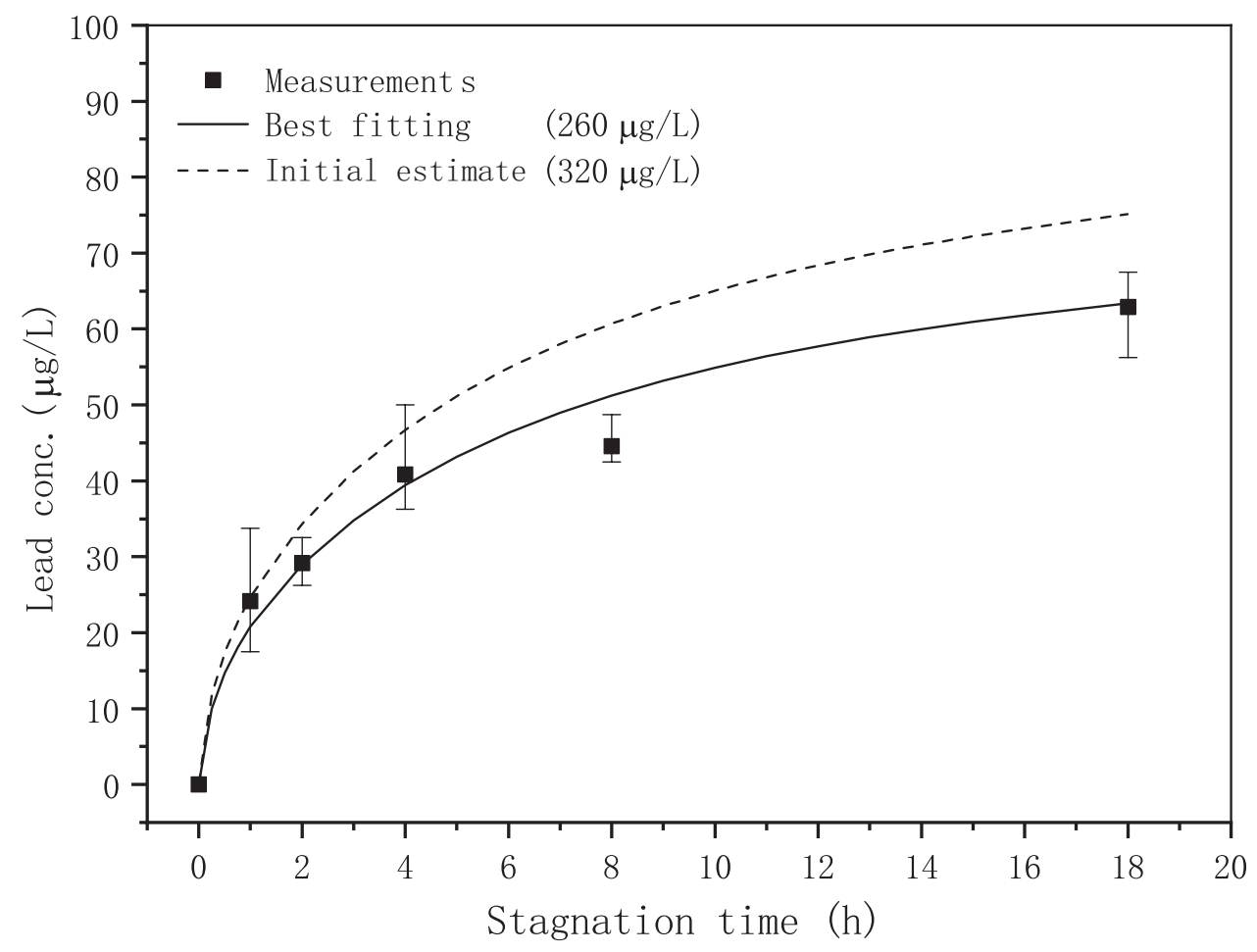

Figure S10: Comparison of numerical prediction with experiment data for a brass valve, initial estimation: $E_{0}=320 \mu \mathrm{g} / L$, best fit: $E_{0}=260 \mu \mathrm{g} / \mathrm{L}$ 


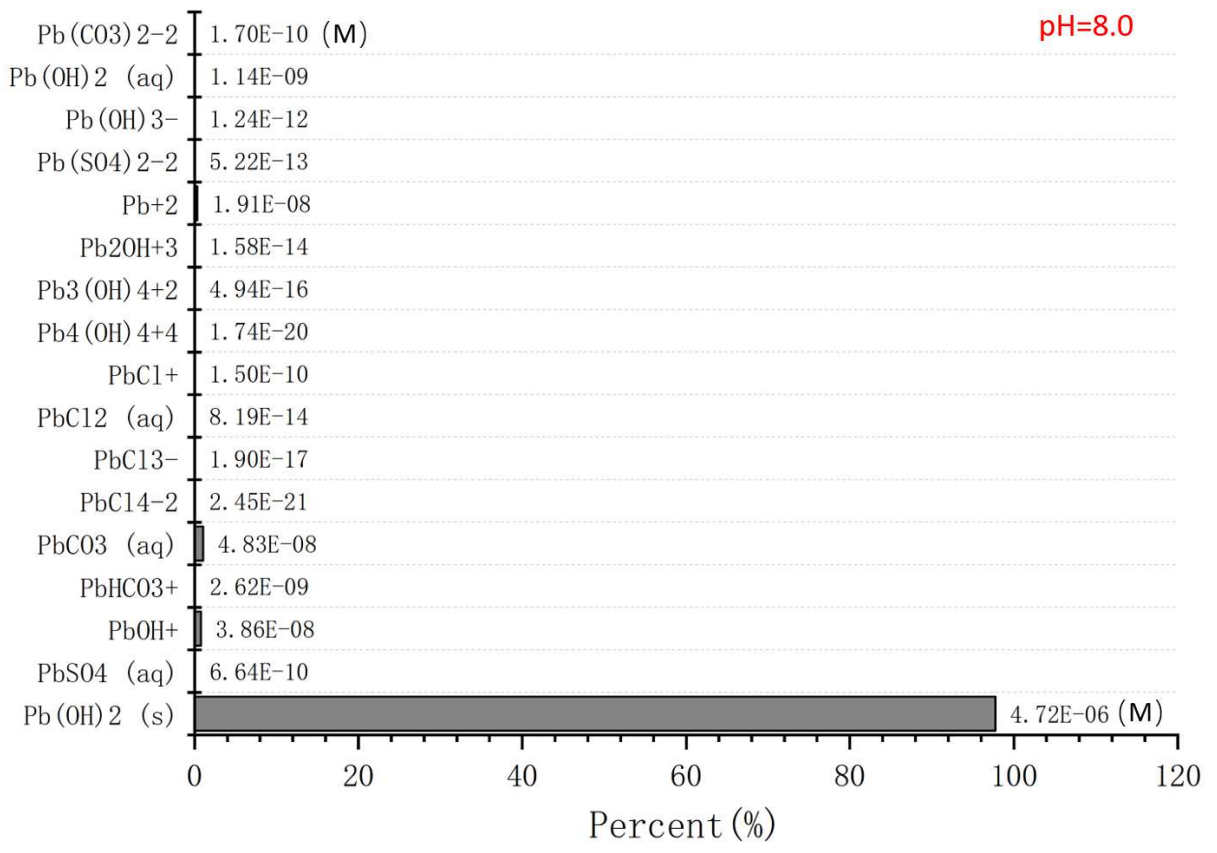

Figure S11: MINTEQ simulation output on $\mathrm{Pb}$ complexes and precipitates (concentrations in $\mathrm{M}$ ) at $\mathrm{pH}=8.0 . \mathrm{Pb}^{2+}=1 \mathrm{mg} / \mathrm{L}$ used for simulation.

\begin{tabular}{lll}
\hline $\mathrm{pH}$ & $\mathrm{C}(\mathrm{M})$ & $\mathrm{C}(\mathrm{mg} / \mathrm{l})$ \\
2 & $9.99 \mathrm{E}-05$ & 20.702 \\
3 & $9.99 \mathrm{E}-05$ & 20.702 \\
4 & $9.99 \mathrm{E}-05$ & 20.702 \\
5 & $9.99 \mathrm{E}-05$ & 20.702 \\
5.2 & $9.99 \mathrm{E}-05$ & 20.702 \\
5.5 & $9.99 \mathrm{E}-05$ & 20.703 \\
5.8 & $6.31 \mathrm{E}-05$ & 13.066 \\
5.9 & $4.62 \mathrm{E}-05$ & 9.564 \\
6 & $3.36 \mathrm{E}-05$ & 6.968 \\
6.1 & $2.45 \mathrm{E}-05$ & 5.070 \\
6.2 & $1.78 \mathrm{E}-05$ & 3.696 \\
6.5 & $6.30 \mathrm{E}-06$ & 1.304 \\
7 & $1.19 \mathrm{E}-06$ & 0.246 \\
7.5 & $4.31 \mathrm{E}-07$ & 0.089 \\
8 & $1.09 \mathrm{E}-07$ & 0.023 \\
9 & $1.00 \mathrm{E}-08$ & 0.002 \\
10 & $1.80 \mathrm{E}-09$ & 0.000 \\
\hline
\end{tabular}

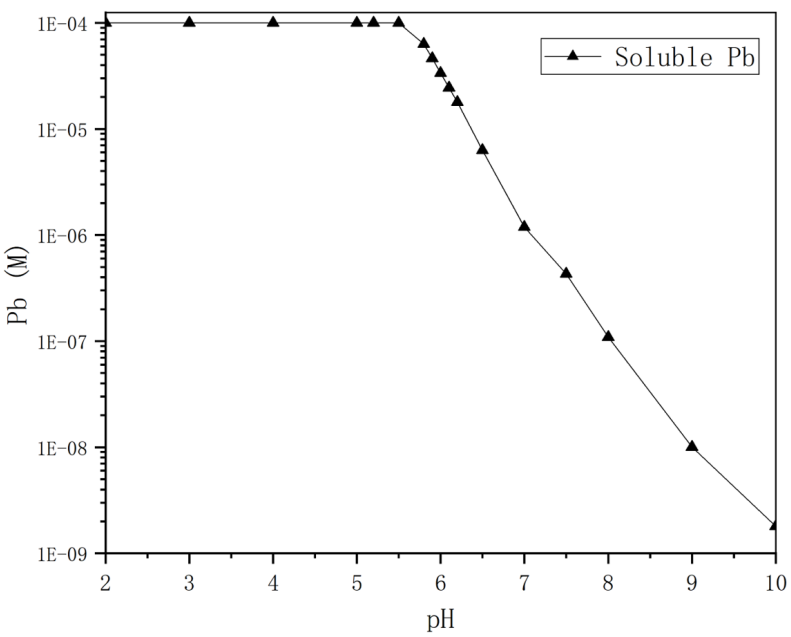

Figure S12: MINTEQ simulation output of soluble $\mathrm{Pb}$ concentrations at different $\mathrm{pH} . \mathrm{Pb}^{2+}=20 \mathrm{mg} / \mathrm{L}$ used for simulation. 


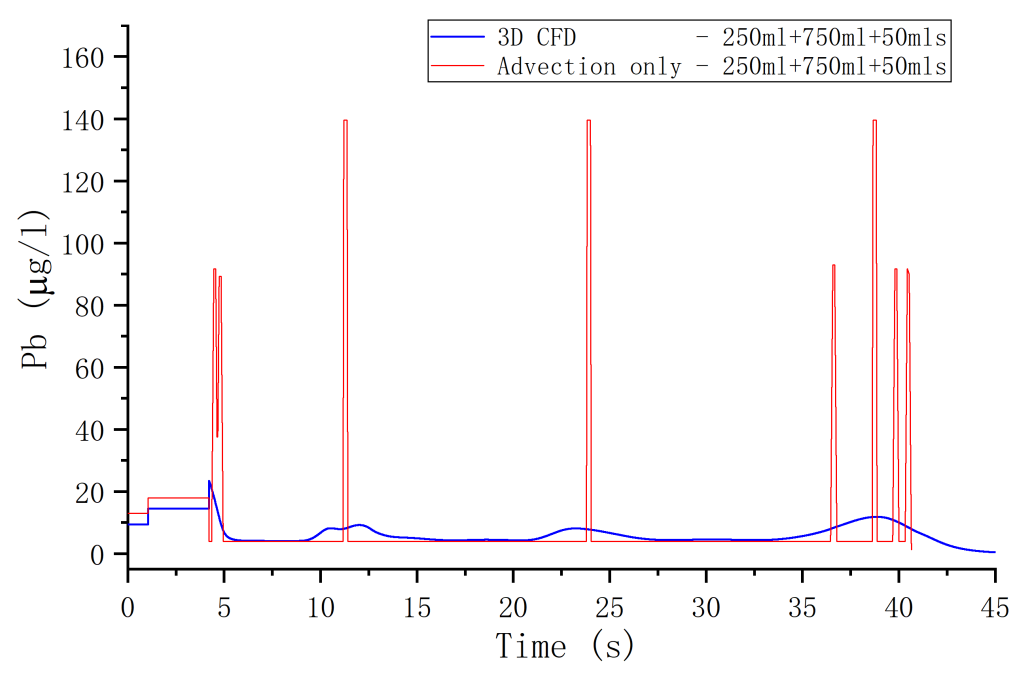

Figure S13: The predicted sample volume averaged $\mathrm{Pb}$ concentration after $4 \mathrm{~h}$ stagnation at tap of Rig $3 \mathrm{C}$ by assuming plug flow (red line) and by $3 \mathrm{D}$ CFD solution (blue line). Flow rate $=240 \mathrm{~mL} / \mathrm{s}(14.4 \mathrm{~L} / \mathrm{min})$

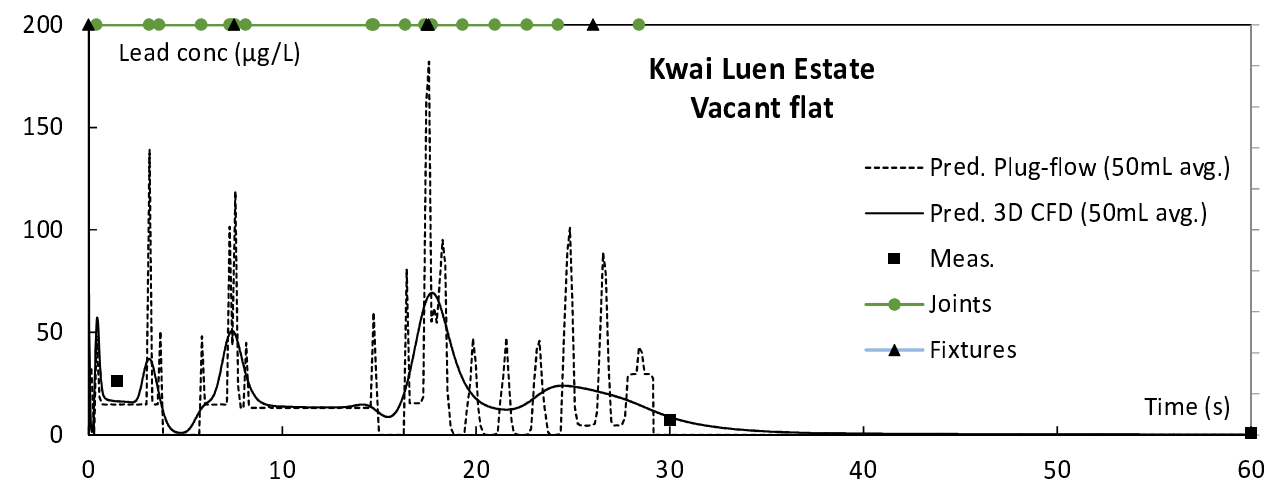

Figure S14: The predicted sample volume averaged $\mathrm{Pb}$ concentration after $18 \mathrm{~h}$ stagnation at tap of a PRH estate vacant flat by assuming plug flow and by $3 \mathrm{D}$ CFD solution. Flow rate $=350 \mathrm{~mL} / \mathrm{s}(21 \mathrm{~L} / \mathrm{min})$ 


\section{Measurement of dissolved and particulate lead}

The experiments were carried out using a copper pipe with a simulated solder joint (CS), and a copper pipe coupled with a brass valve at the middle (CV) (Fig. S9). The simulated solder joint is made by attaching two discs made of $\mathrm{Sn}-\mathrm{Pb}$ solder on the inner surface of copper pipe by conductive glue. The copper pipe diameter is $20 \mathrm{~mm}$ and the pipe length is $0.6 \mathrm{~m}$. Before the experiment, the test pipes were rinsed and flushed by tap water for at least five times. Then the pipes were filled with tap water and left to stand for a designed period of time. At the end of the stagnation period, all water in the test pipes were collected after full mixing for lead concentration measurement.

Particulate lead concentration was measured according to the following procedure: (i) Each sample was first filtered by $0.8 \mu \mathrm{m}$ mixed cellulose ester (MCE) membrane filter; then by $0.2 \mu \mathrm{m}$ membrane filter. (ii) The MCE filters were digested in beaker by adding $5 \mathrm{~mL}$ concentrated $69 \%$ nitric acid $\left(\mathrm{HNO}_{3}\right)$ and boiled until no more brown fume comes out. (iii) After boiling, the solution (around $1 \mathrm{~mL}$ ) was transferred to $25 \mathrm{~mL}$ volumetric flask and filled by distilled water to the mark. The diluted sample was then transferred to a clean sample bottle and the $\mathrm{Pb}$ concentration was measured; the particulate $\mathrm{Pb}$ concentration in the original sample can hence be determined. (iv) For the filtrate passing through $0.2 \mu \mathrm{m}$, concentrated $69 \% \mathrm{HNO}_{3}$ was added to the filtrate to $\mathrm{pH}<2$ and the soluble $\mathrm{Pb}$ concentration was measured.

The soluble lead and particulate lead concentrations using $0.8 \mu \mathrm{m}$ filter pore size are shown in Table S2, while those using $0.2 \mu \mathrm{m}$ as cut-off size are shown in Table S3. The results using both cut-off sizes show more than $70 \%$ of the total lead concentration is contributed by soluble lead; using a cut-off size of $0.2 \mu \mathrm{m}$ increases the percentage lead contribution of particulates (relative to total $\mathrm{Pb}$ ) by an average of $6.3 \%$ (maximum $17 \%$ ).

For the sampling experiments in real-life water supply systems, the SEM images show that the major lead-containing pipe scales are cerussite and hydrocerussite (Fig. 8 of the paper). Studies have found that in the pipelines where hydrocerussite is the dominant species, the total lead concentration was primarily dissolved lead under both stagnant and laminar flow conditions (Xie and Giammar, 2011). 
Table S2: Measured soluble and particulate lead concentrations in stagnation leaching experiments of pipe section coupled with: (i) brass valve (CV); and (ii) simulated solder (CS) using $0.8 \mu \mathrm{m}$ as cutoff size

\begin{tabular}{|l|l|l|l|l|l|l|}
\hline & & & \multicolumn{2}{l|}{ soluble $(<0.8 \mu \mathrm{m})$} & \multicolumn{2}{l|}{ particulate $(>0.8 \mu \mathrm{m})$} \\
\hline \multirow{5}{*}{ CV pipe } & $\begin{array}{l}\text { Stagnation } \\
\text { time }(\mathrm{h})\end{array}$ & Total $(\mu \mathrm{g} / \mathrm{L})$ & $\mathrm{Pb}(\mu \mathrm{g} / \mathrm{L})$ & $\%$ of total & $\mathrm{Pb}(\mu \mathrm{g} / \mathrm{L})$ & $\%$ of total \\
\cline { 2 - 7 } & 4 & 7.0 & 5.8 & 82.9 & 1.2 & 17.1 \\
\cline { 2 - 7 } & 4 & 9.9 & 8.8 & 88.9 & 1.1 & 11.1 \\
\cline { 2 - 7 } & 12 & 13.3 & 10.4 & 78.2 & 2.9 & 21.8 \\
\cline { 2 - 7 } & 12 & 11.7 & 10.0 & 85.5 & 1.7 & 14.5 \\
\cline { 2 - 7 } & 24 & 26.9 & 19.9 & 74.0 & 7.0 & 26.0 \\
\hline \multirow{5}{*}{ CS pipe } & 24.8 & 29.6 & 90.2 & 3.2 & 9.8 \\
\cline { 2 - 7 } & 12 & 319.6 & 282.4 & 88.4 & 37.2 & 11.6 \\
\hline
\end{tabular}

Table S3: Measured soluble and particulate lead concentrations in stagnation leaching experiments of pipe section coupled with: (i) brass valve $(\mathrm{CV})$; and (ii) simulated solder (CS) using $0.2 \mu \mathrm{m}$ as cutoff size

\begin{tabular}{|l|l|l|l|l|l|l|}
\hline & \multirow{2}{*}{$\begin{array}{l}\text { stagnation } \\
\text { time }(\mathrm{h})\end{array}$} & & \multicolumn{2}{|c|}{ soluble $(<0.2 \mu \mathrm{m})$} & \multicolumn{2}{l|}{ particulate $(>0.2 \mu \mathrm{m})$} \\
\cline { 2 - 7 } & Total $(\mu \mathrm{g} / \mathrm{L})$ & $\mathrm{Pb}(\mu \mathrm{g} / \mathrm{L})$ & $\%$ of total & $\mathrm{Pb}(\mu \mathrm{g} / \mathrm{L})$ & $\%$ of total \\
\hline \multirow{5}{*}{ CV pipe } & 4 & 7.0 & 5.2 & 74.3 & 1.8 & 25.7 \\
\cline { 2 - 7 } & 4 & 9.9 & 8.3 & 83.8 & 1.7 & 17.2 \\
\cline { 2 - 7 } & 12 & 13.4 & 9.5 & 70.9 & 3.9 & 29.1 \\
\cline { 2 - 7 } & 12 & 11.7 & 9.4 & 80.3 & 2.3 & 19.7 \\
\cline { 2 - 7 } & 24 & 26.9 & 19.3 & 71.7 & 7.6 & 28.3 \\
\cline { 2 - 7 } & 24 & 32.8 & 24.0 & 73.2 & 8.8 & 26.8 \\
\hline \multirow{3}{*}{ CS pipe } & 12 & 319.6 & 272.1 & 85.1 & 47.5 & 14.9 \\
\cline { 2 - 7 } & 12 & 286.6 & 266.7 & 93.1 & 19.9 & 6.9 \\
\hline
\end{tabular}

